\title{
Kinetic Study of Garlic and Ginger Particles in Adsorption of Heavy Metals in Aqueous Solution
}

\author{
Kenneth Kekpugile.Dagde* Jonah Igwe Ndaka \\ Department of Chemical and Petrochemical Engineering, Rivers State University, \\ Port Harcourt, Rivers State, Nigeria
}

\begin{abstract}
This study involved investigation and comparison of the capacity of garlic and ginger particles in adsorption of lead, cadmium and chromium ions from contaminated water. This was motivated by the perennial contamination of well water by crude oil, which carried alongside heavy metals from earth surface and other sources in contact with it while discharging from oil facilities to the subsurface region. Heavy metal analysis on the well water and crude oil from the polluted site showed high level of heavy contamination. Effect of initial concentration of heavy metals, adsorbents dosage and contact time on adsorption of the lead, cadmium and chromium ions in aqueous solution by garlic and ginger particles were studied. Garlic and ginger particles adsorption process was studied using Langmuir and Temkin isotherms. Also, to describe the kinetics of the adsorption process, the Pseudo first and second order kinetics as well as the intra-particle diffusion kinetics were used to study the experimental data. The analysis showed that the percentage of lead, cadmium and chromium ions adsorbed by garlic and ginger particles decreased as the initial concentration of metals in solution and contact time were increased. Similarly, the percentage of lead, cadmium or chromium ions adsorbed by the garlic and ginger particles at equilibrium increased as adsorbent dosages was increased due to increased effective surface area of the adsorbent. Equilibrium was attained at about 60 minutes with either garlic or ginger particles. However, garlic particles adsorbed the heavy metals more than the particles of ginger at all conditions. Also, it was observed that lead ion has more affinity to both garlic and ginger particles followed by cadmium ion. The adsorption of lead, cadmium and chromium ions were better explained by the Langmuir isotherm model than the Temkin's isotherm model. The maximum adsorption capacity for lead, cadmium and chromium ions with garlic particles were $3.9308 \mathrm{mg} / \mathrm{g}, 3.3223 \mathrm{mg} / \mathrm{g}$ and $1.992 \mathrm{mg} / \mathrm{g}$ while that of ginger particles were $2.9011 \mathrm{mg} / \mathrm{g}, 2.3121 \mathrm{mg} / \mathrm{g}$ and $1.9543 \mathrm{mg} / \mathrm{g}$ respectively. The adsorption of lead, cadmium and chromium ions in the solution of both adsorbents revealed that diffusion and chemisorptions occurred in the adsorption process, which was best fitted in the Pseudo second order kinetics. Indicating that the Pseudo second order kinetics was the rate controlling step, and thus, will predict accurately the concentration of metal ions adsorbed. Conclusively, the garlic and ginger particles showed capacity for the removal of lead, cadmium and chromium in aqueous solution, and therefore are recommended for use in adsorption of heavy metals in wastewater.
\end{abstract}

Keywords: Garlic, Ginger, Heavy metals, Adsorption Isotherm, Kinetics

DOI: $10.7176 / \mathrm{CPER} / 60-04$

Publication date:March $31^{\text {st }} 2019$

\section{Introduction}

Globally, greater percentage of the world populace utilizes underground water as the major source for drinking and other domestic use (Choi et al., 2011; De Gusseme et al., 2011). It is also used for irrigational farming (Herlekar and Barve, 2015). Most groundwater is clean, but can become contaminated as a result of human activities or through natural conditions.

There are many ways groundwater can be polluted, but activities of humans produce innumerable waste materials and by-products. Most of these wastes are disposed of without regulatory controls, and even worse, some are disposed or stored on land surfaces untreated. Also, some technological practices impact negatively on underground water, such as spills from industrial operations, application of fertilizers or pesticides, infiltration from urban runoff, and leakage from landfills (Mehra et al., 2016). When these wastes percolate into the underlying groundwater, it contaminates groundwater thereby, making it unsafe for use.

Another worrying source of water contamination especially in the Niger Delta region of Nigeria is hydrocarbon pollution. Hydrocarbon exploration and production activities by the multinational companies have greatly contributed to the pollution of the environment. When large volume of oil is released onto the soil surface, it carries particles and other impurities including heavy metals into groundwater aquifer. Study has shown that during oil spill, heavy metals are carried from the soil surface by crude oil (Ndamitso et al., 2016).

Due to oil pollution in Ogoni, Rivers State, communities around the oil polluted sites have decried on the increasing rate of groundwater contamination thereby, prompting concerned individuals and organizations to finding the best possible techniques in successfully bringing the environment, including underground water, to acceptable limit recommended by Standard Organizations.

The contamination of groundwater is hazardous to public health, which can cause the spread of diseases, but 
fortunately, techniques have been developed to address this issue (Ujile and Owhor, 2018). One of such techniques is the adsorption technology, where contaminants in solution are adsorbed onto solid particles. Adsorption is not only a simple remediation process, it is also environmental friendly and cost-effective (Ndamitso et al., 2016).

Various studies have been carried out for adsorption of metal in aqueous solution. Chowdhury et al. (2012) compared the performance of onion and garlic skins for the removal of $\mathrm{Cu}^{2+}$ from aqueous solution, and recorded maximum adsorption with onion skin. Similar study has also reported high efficiency of onion and garlic wastes in the removal of different heavy metals from aqueous solution (Negi et al. (2012). The removal efficiency of $\mathrm{Pb}^{2+}$, $\mathrm{Cu}^{2+}$, and $\mathrm{Ni}^{2+}$ by garlic peel has also been reported (Liang et al. (2013).

However, while considering adsorbent for removal of heavy metals, interest should not only be on the low cost, but also on the removal efficiency of metal from solution by the adsorbent. Ujile and Okwakwam (2018) has shown that agro-based industrial waste called dry empty oil palm bunch (DEOPB), used as adsorbent for the removal of lead, iron, copper and cadmium in industrial waste effluent was not able to adsorbed lead from its solution.

Therefore, this research investigated the potency of garlic and ginger particles in removal of lead, cadmium and chromium from contaminated well water located in oil polluted area.

\section{Materials and Methods \\ 2.1 Sample Collection}

Well water was collected from hand dug well that is very close to crude oil polluted site in Kpean (one of the major oil producing Communities in Nigeria) Community in Khana Local Government Area of Rivers State, while ginger (Zingiber Officinale) and garlic (Allium Sativum) plants were obtained from local Market in Rivers State, Nigeria.

\subsection{Preparation of Garlic and Ginger Particles}

The adsorbents were prepared according to the method described by Sharma et al. (2016). The garlic and ginger were first sun-dried for 2 days and further dried in oven at controlled temperature of $70-100^{\circ} \mathrm{C}$ for 4 hours to expel moisture content. After drying, they were washed to remove dirt, and then further dried in preparation for crushing. After crushing to fine powdered particles, they were sieved through $0.18 \mathrm{~mm}$ mesh to obtain a uniform particle size. The grinded particles of the garlic and ginger were soaked in $0.1 \mathrm{~N} \mathrm{NaOH}$ for 9 hours and washed again with distilled water to remove lignin and then dried. The particles were further washed with distilled water and soaked with $0.1 \mathrm{M}$ of $\mathrm{H}_{2} \mathrm{SO}_{4}$ for another 9 hours to remove traces of alkalinity, and then washed thoroughly with distilled water again. After washing, they were then sun-dried and stored in desiccator in preparation for the adsorption experiment.

\subsection{Physicochemical Analysis of Samples}

The atomic absorption spectrophotometer (AAS) was used to determine heavy metal present in the well water sample.

\subsection{Batch Adsorption}

\subsubsection{Adsorbent Dosage}

Different weighs of $0.2 \mathrm{~g}, 0.5 \mathrm{~g}, 0.8 \mathrm{~g}$ and $1.0 \mathrm{~g}$ of the treated crushed garlic particles were separately weighed. Four (4) conical flasks which served as reactors were arranged and a measured $100 \mathrm{ml}$ volume of distilled water was added into each of the reactors, followed by $10 \mathrm{mg} / 1$ of lead ion. Thereafter, the corresponding doses of garlic particles were separately added to the reactors. The $\mathrm{pH}$ and average room temperature of the solutions were measured at 6.5 and $28^{\circ} \mathrm{C}$ respectively. The solution in the reactors were vigorously agitated for proper contacting of the particles and lead ion in the solution. After attaining equilibrium, the suspension was filtered through filter paper. The filtrate was subjected to analysis in order to determine the concentration of lead ion remaining in the liquid solution using Atomic Absorption Spectrophotometer (Model-Perkin Elmer, AAS, Pin AAcle 900 K). The process was repeated for the analysis of cadmium and chromium ions and with the use of ginger particles adsorbent.

\subsubsection{Initial Metal Ion Concentration}

The effect of initial concentration of lead, cadmium and chromium ions was investigated at only $1.0 \mathrm{~g}$ dose of the treated garlic or ginger particles. All other procedures used for the effect of adsorbent dosage were repeated, but five (5) reactors were used containing separate concentrations of $10 \mathrm{mg} / 1,20 \mathrm{mg} / 1,30 \mathrm{mg} / 1,40 \mathrm{mg} / 1 \mathrm{and} 50 \mathrm{mg} / 1 \mathrm{of}$ the respective heavy metal ions in the solution.

\subsubsection{Contact Time}

Similarly, effect of contact time on adsorption of the metals ions by garlic and ginger particles were investigated at only $1.0 \mathrm{~g}$ adsorbent dosage and $10 \mathrm{mg} / 1$ initial concentration. Again, all other procedures used in the previous investigations were followed. Here, six (6) reactors were used. At every 30 minute intervals, the suspension in one of the reactors was filtered through filter paper, and the filtrate analysed to determine the concentration of heavy 
metal ion remaining in the solution. This process was conducted independently for all the metals.

The percentage of lead, cadmium and chromium ions adsorbed by garlic or ginger particles in all the cases were calculated using the formulas expressed in the work of Ademiluyi and Ujile (2013).

Adsorbed metal $(\%)=\frac{C_{i}-C_{f}}{C_{i}} \times 100 \%$

Also, the adsorption capacity of particles of garlic and ginger at equilibrium were calculated using the formula expressed in the work of Ademiluyi and Ujile (2013).

$$
Q_{e}=\left(C_{i}-C_{e}\right) \frac{V}{w}
$$

However, for effect of contact time, the adsorption capacity at any time was calculated using formula:

$$
Q_{t}=\left(C_{i}-C_{t}\right) \frac{V}{w}
$$

where: $Q_{e}=$ Adsorption capacity at equilibrium $(\mathrm{mg} / \mathrm{g}), Q_{t}=$ Adsorption capacity at time, $t(\mathrm{mg} / \mathrm{g}), C_{f}=$ Final concentration of metal ion in the liquid mixture $(\mathrm{mg} / \mathrm{l}), C_{i}=$ Initial concentration of metal ion in the liquid mixture $(\mathrm{mg} / \mathrm{l}), C_{e}=$ Concentration of metal ion in the liquid mixture at equilibrium $(\mathrm{mg} / \mathrm{l}), V=$ Volume of liquid mixture (1), $w=$ Weight of adsorbent (g).

\subsection{Adsorption Isotherm}

The Langmuir and Temkin isotherm models were applied to study adsorption of heavy metals using garlic and ginger particles.

\subsubsection{Langmuir Isotherm Model}

The Langmuir isotherm model is expressed in the work of Ademiluyi and Ujile (2013) as:

$$
\frac{C_{e}}{Q_{e}}=\frac{C_{e}}{Q_{m}}+\frac{1}{K_{L} Q_{m}}
$$

A plot of $\frac{C_{e}}{Q_{e}}$ versus $C_{e}$ gives a straight line graph with slope equivalent to $\frac{1}{Q_{m}}$ and the intercept as $\frac{1}{K_{L} Q_{m}}$.

where: $Q_{m}=$ Langmuir constants at maximum adsorption capacity of kerosene $(\mathrm{mg} / \mathrm{g})$ and $K_{L}=$ Energy of adsorption (1/mg).

\subsubsection{Temkin Isotherm Model}

The Temkin isotherm model is expressed according to Sharma et al. (2016) as:

$$
Q_{e}=\frac{R T}{b} \ln \left(A C_{e}\right)
$$

Equation (5) can be expanded as follows:

$$
Q_{e}=\frac{R T}{b} \ln A+\frac{R T}{b} \ln C_{e}
$$

Further simplification yields:

$$
Q_{e}=B \ln A+B \ln C_{e}
$$

Where:

$$
B=\frac{R T}{b}
$$

The plot of $Q_{e}$ against $\ln C_{e}$ gives the slope as: $B=\frac{R T}{b}$ and the intercept as $B \ln A$.

B can be directly obtained from the slope of the graph, while A can be obtained by further manipulation of the intercept as follows:

$$
A=\exp \left(\frac{C}{B}\right)
$$

where: $C$ is the intercept obtained from the linear equation, $R=$ gas constant $(\mathrm{J} / \mathrm{mol} . \mathrm{K}), T=$ adsorption 
temperature $(\mathrm{K}), b=$ constant relating to adsorption energy across the adsorbent surface $(\mathrm{J} / \mathrm{mol})$ and $A=$ Temkin constant relating to adsorption capacity $(1 / \mathrm{mg})$.

2.6 Adsorption Kinetics

Like adsorption isotherm, the pseudo first and second order kinetic as well as the intra-particle diffusion models were applied to study adsorption of heavy metals onto garlic and ginger particles.

\subsubsection{Pseudo First Order Kinetics}

The Lagergren's pseudo first order equation expressed by Ho (2004) was used, and it is given as:

$$
\frac{d Q_{t}}{d t}=k_{1}\left(Q_{e}-Q_{t}\right)
$$

where: $k_{1}=$ pseudo first order adsorption rate constant $\left(\mathrm{min}^{-1}\right), Q_{e}=$ concentration of heavy metal adsorbed by the adsorbent at equilibrium $(\mathrm{mg} / \mathrm{g}), Q_{t}=$ concentration of heavy metal adsorbed by the adsorbent with time $(\mathrm{mg} / \mathrm{g}), t=$ measured time of adsorption ( $\mathrm{min})$.

Further arrangement gives:

$$
\log \left(Q_{e}-Q_{t}\right)=\log Q_{e}-k_{1} t
$$

The plot of $\log \left(Q_{e}-Q_{t}\right)$ versus $t$ gives slope equivalent to $k_{1}$ and intercept equivalent to $\log Q_{e}$.

\subsubsection{Pseudo Second Order Kinetics}

The pseudo second order model is expressed according to Ho (2004).

$$
\frac{d Q_{t}}{d t}=k_{2}\left(Q_{e}-Q_{t}\right)^{2}
$$

where, $k_{2}=$ Pseudo second order adsorption rate constant (g/gm.min). Every other parameter remained as defined previously. The solution to equation (12) is given as:

$$
\frac{t}{Q_{t}}=\frac{t}{Q_{e}}+\frac{1}{Q_{e}^{2} k_{2}}
$$

The plot of $\frac{t}{Q_{t}}$ against $t$ gives slope equivalent to $\frac{1}{Q_{e}}$ and intercept equivalent to $\frac{1}{Q_{e}^{2} k_{2}}$.

\subsubsection{Intra-Particle Diffusion Model}

The intra-particle diffusion kinetics developed by Weber and Morris in 1963 was used, and it is expressed according to Pasavant et al. (2006) as:

$$
Q_{t}=K_{d} \sqrt{t}
$$

where: $Q_{t}=$ The amount adsorbed at time $\mathrm{t}(\mathrm{mg} / \mathrm{g}), K_{d}=$ Weber and Morris intra-particle diffusion rate constant (mg/g. $\left.\min ^{0.5}\right)$ and $t=$ Time of adsorption (min).

The plot of $Q_{t}$ versus $t^{1 / 2}$ gives a slope equivalent to $K_{d}$, and the linearity of the plot is an indication that the adsorption follows intra-particle diffusion. However, when the linear plot does not pass through the origin, it means that intra -particle diffusion is not the rate controlling step (Pasavant et al., 2006; Ademiluyi and Ujile, 2013).

\section{Results and Discussion}

3.1 Heavy Metal Composition in the Well Water

The AAS analysis performed to determine the heavy metal composition in the well water is presented in Table 1.

\begin{tabular}{ll}
\multicolumn{2}{c}{ Table 1: Heavy Analysis of Polluted Well water } \\
\hline Parameter & Value \\
\hline Lead, $\mathrm{Pb}(\mathrm{mg} / \mathrm{l})$ & 21.8349 \\
$\mathrm{Zinc}, \mathrm{Zn}(\mathrm{mg} / \mathrm{l})$ & 5.1052 \\
Cadmium, Cd (mg/l) & 10.5738 \\
Chromium, Cr (mg/l) & 28.1912 \\
Copper, Cu (mg/l) & 8.1461 \\
Manganese, Mn (mg/l) & 2.3161 \\
Nickel, $\mathrm{Ni} \mathrm{(mg/l)}$ & 15.7393 \\
Cobalt, Co (mg/l) & 6.2716 \\
\hline
\end{tabular}

The concentrations of heavy metals composition in the well water were very high. This was due to the level 
of crude oil pollution around the investigated well, which had carried alongside, heavy metal deposition on the soil surface into the well.

\subsection{Effect of Initial Concentration on Adsorption Capacity of Adsorbents}

Effect of initial concentration of heavy metals on the adsorption capacity of garlic and ginger particles at equilibrium is shown in Figures 4.1 and 4.2.

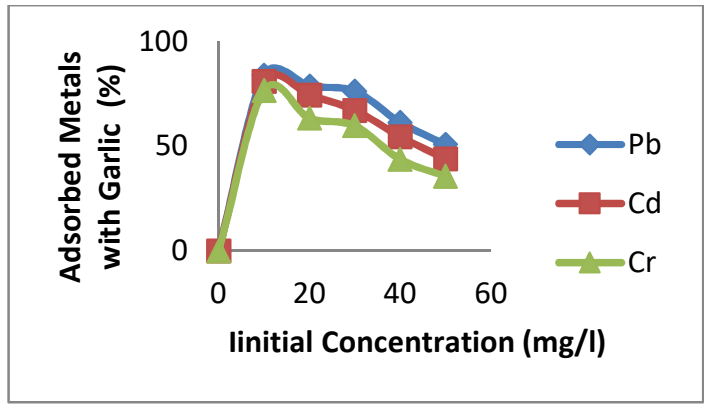

Figure 1: Effect of Initial Concentration on Metallic Ions Removal Using Garlic

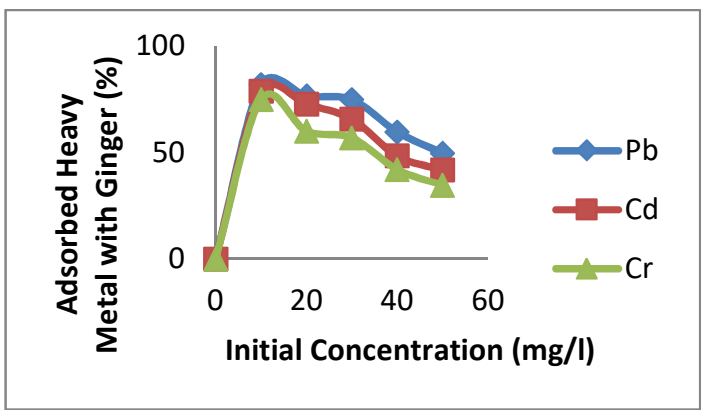

Figure 2: Effect of Initial Concentration on Metallic Ions Removal Using Ginger

There was remarkable reduction of metals concentration in the solution, indicating that particles of garlic and ginger were promising adsorbents for heavy metals removal in aqueous solution. Figure 1 shows the percentage of lead, cadmium and chromium ions adsorbed by garlic particles from the solution at various initial concentrations of the metals, while Figure 2 shows the percentage of the metals adsorbed by ginger particles in same solution. In both cases, increased in initial concentration of metals in solution decreases the amount of metals removed by the garlic and ginger particles. Thus, the concentration of lead adsorbed by garlic from the solution at equilibrium decreased from $83.89 \%$ to $50.82 \%$, while for cadmium and chromium, the concentration adsorbed at equilibrium decreased from $80.92 \%$ to $43.88 \%$ and $76.51 \%$ to $35.65 \%$ respectively, as initial concentration in the solution was increased from $10 \mathrm{mg} / 1$ to $50 \mathrm{mg} / 1$. Similar scenario was observed with ginger particles. Thus at equilibrium, the concentrations of lead, cadmium and chromium adsorbed by the ginger particles decreased from 81.89 to $49.67 \%$, 78.86 to $41.69 \%$ and 74.91 to $34.61 \%$ respectively as concentration in the solution was increased from $10 \mathrm{mg} / 1$ to $50 \mathrm{mg} / \mathrm{l}$.

The reductions in percentage adsorption of metals by the adsorbents were attributed to the increased amount of contaminants in the solution. Thus, it implied that there was not enough space for the adsorbent to take up more of the metals at the given dosage. This observation was reported in previous studies (Ademiluyi and Ujile (2013; Sharma et al. 2016). However on the contrary, Kumar and Shrivastava (2015) reported an increase of chromium ion removal percentage as initial concentration of chromium in the aqueous solution was increased.

\subsection{Effect of Adsorbent Dosage}

The effect of garlic and ginger dosage on the removal of lead, cadmium and chromium ions had been investigated at $10 \mathrm{mg} / \mathrm{l}$ initial concentration. The percentage amount of heavy metal ions adsorbed by garlic and ginger particles at equilibrium is shown in Figure 3. 


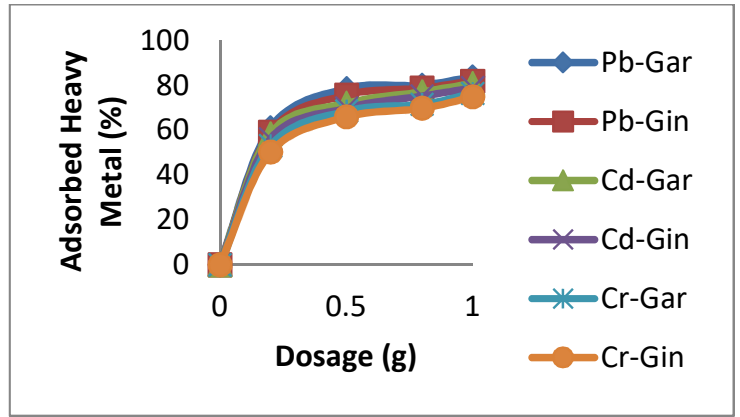

Figure 3: Combined Profiles of Adsorbed Metals by Adsorbents at Varying Dosage

Figure 3 shows that increase in adsorbent dosage both garlic and ginger particles consequently increased the adsorption of the metals. This trend had also been reported in many studies for the removal of heavy metals by other modified particles of plants (Kumar et al., 2010; Chowdhury et al., 2012; Ademiluyi and Ujile, 2013 and Sharma et al., 2016). This was attributed to overlapping of adsorption sites due to over-crowding of adsorbent particles, or increase in effective surface area and conglomeration of the adsorbent (Kumar et al., 2010; Ademiluyi and Ujile, 2013).

Thus, as dosage increased from 0.2 to $1.0 \mathrm{~g}$ at equilibrium, the percentages of lead removed by garlic particles increased from 61.16 to $83.89 \%$. Also, the percentages of cadmium and chromium adsorbed by garlic particles using at same conditions increased from 58.53 to $80.92 \%$ and 53.15 to $76.51 \%$ respectively. Similarly, with ginger particles, the percentages of lead, cadmium and chromium adsorbed at same conditions increased from 59.26 to $81.89 \%, 56.14$ to $78.86 \%$ and 50.21 to $74.91 \%$ respectively. Although both adsorbents were effective, garlic particles adsorbed the metals in solution than ginger particles at all doses. Again, both garlic and ginger particles have high affinity to lead than cadmium and chromium. Earlier study had reported high affinity of soursop peel to lead (Ndamitso et al., 2016).

\subsection{Effect of Contact Time on the Adsorption of Heavy Metals}

The effect of contact time on the adsorption of lead, cadmium and chromium ions by particles of garlic and ginger are shown in Figures 4 to 6.

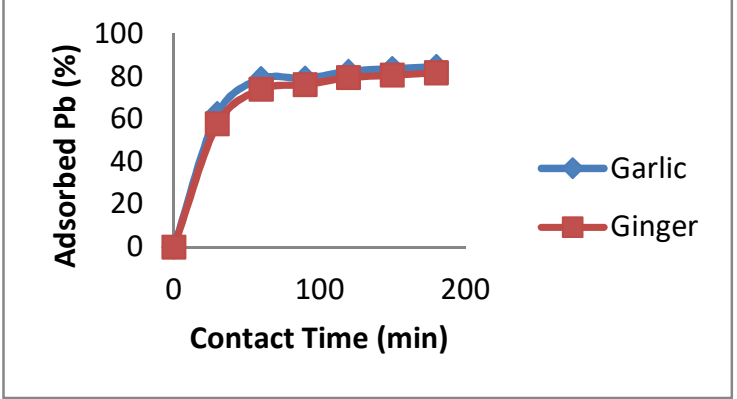

Figure 4: Effect of Contact Time on Lead Adsorption in Solution

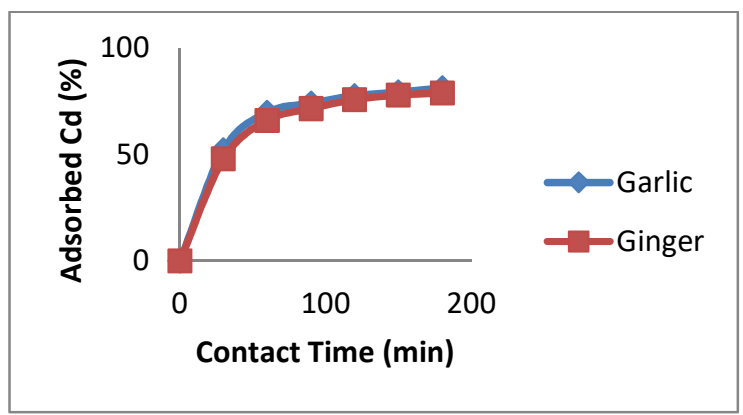

Figure 5: Effect of Contact Time on Cadmium Adsorption in Solution 


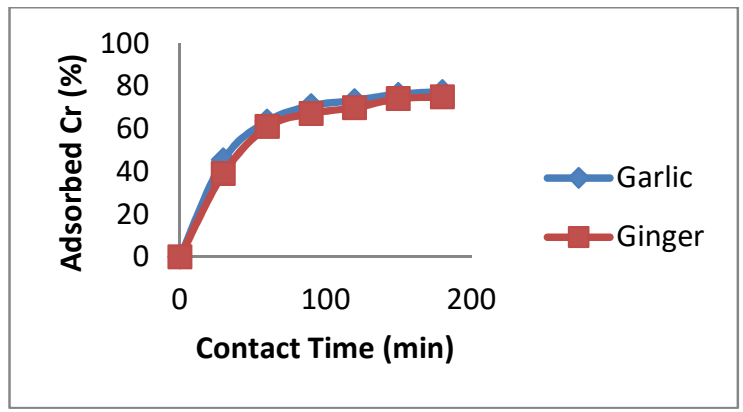

Figure 6: Effect of Contact Time on Chromium Adsorption in Solution

It was observed as shown in the Figures 4 to 6 that particles of garlic were more effective for the removal of heavy metal ions from the solution. However, the percentage of heavy metal ions adsorbed by both adsorbents increased with time. It was also observed that the percentage of ions adsorbed reached equilibrium at about 60 minutes for both adsorbents.

Other researchers have reported equilibrium a longer contact time of 3 hours for removal of manganese (Geetha and Belagali, 2010) and 175 minutes for removal of chromium ion (Kumar and Shrivastava, 2015), while Liang et al. (2013) achieved equilibrium even at a shorter time of 20 minutes in the removal of lead ion from aqueous solution with garlic adsorbent.

However, the percentages of lead ion adsorbed within 30 minutes and at 180 minutes were $62.54 \%$ and $84.65 \%$ (with garlic particles); $57.83 \%$ and $81.73 \%$ (with ginger particles). Similarly, the percentages of cadmium ion adsorbed within 30 minutes and at 180 minutes were $52.23 \%$ and $81.31 \%$ (with garlic particles); $48.03 \%$ and $78.95 \%$ (with ginger particles), while the percentages of chromium ion adsorbed within 30 minutes and at 180 minutes were $45.55 \%$ and $77.48 \%$ (with garlic particles); and $39.12 \%$ and $75.01 \%$ (with ginger particles).

\subsection{Langmuir Isotherm}

The Langmuir isotherm for adsorption of lead, cadmium and chromium ions in solution onto garlic and ginger particles is shown in Figures 7 to 12.

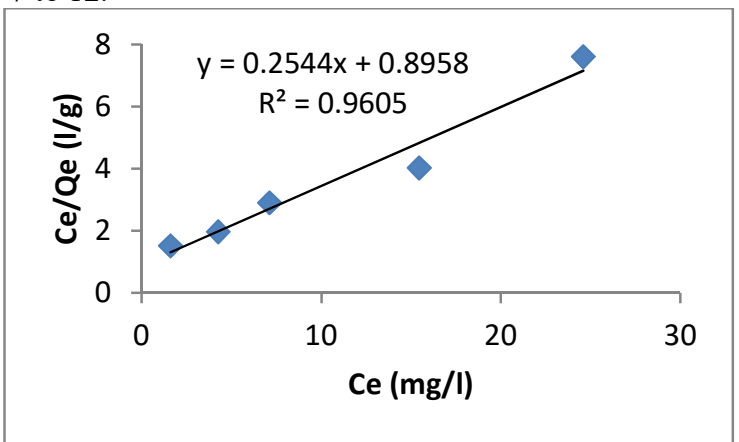

Figure 7: Langmuir Isotherm for Lead Using Garlic

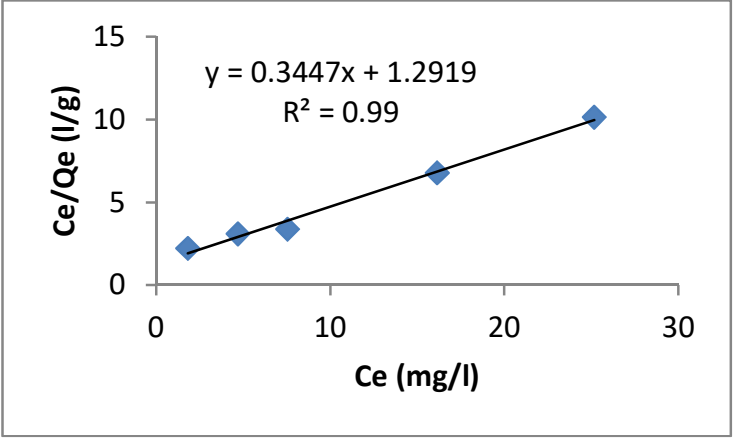

Figure 8: Langmuir Isotherm for Lead Using Ginger 


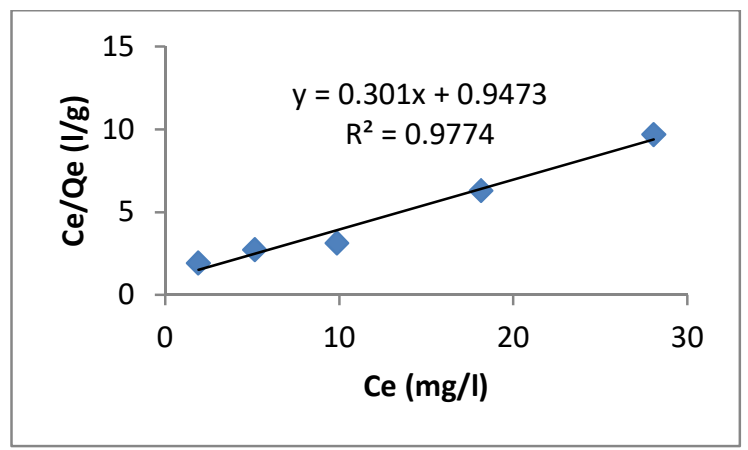

Figure 9: Langmuir Isotherm for Cadmium Using Garlic

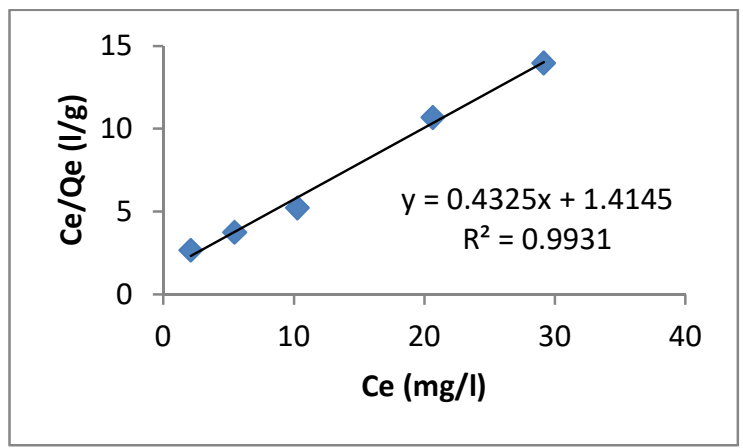

Figure 10: Langmuir Isotherm for Cadmium Using Ginger

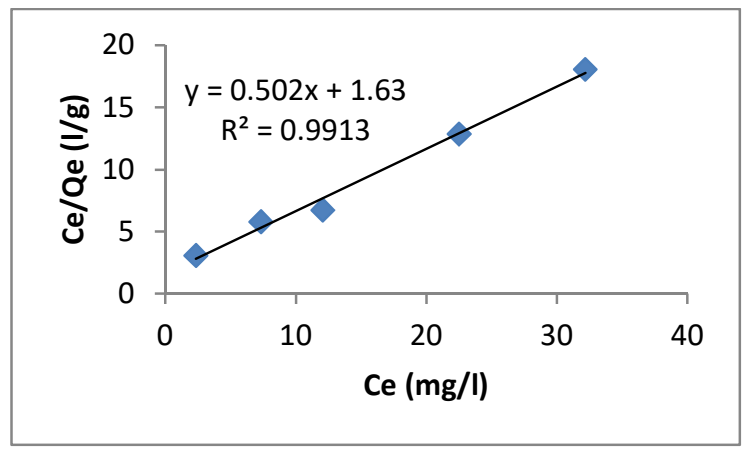

Figure 11: Langmuir Isotherm for Chromium Using Garlic

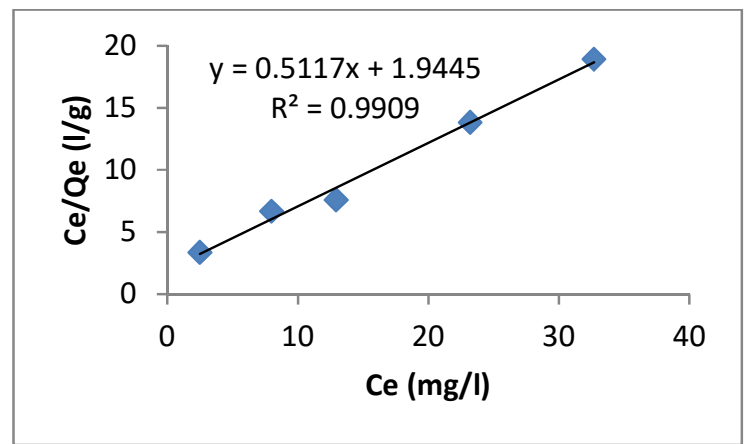

Figure 12: Langmuir Isotherm for Chromium Using Ginger

The linearity of the plot for Langmuir isotherm at equilibrium showed that the Langmuir isotherm model actually described the adsorption process. The rate of adsorption increased as concentration of metals in solution was increased. The adsorption parameters of garlic and ginger particles are summarized in Table 2. 
Table 2: Summary of Langmuir Isotherm Model Parameters

\begin{tabular}{lllllll}
\hline Meta & \multicolumn{2}{c}{$\mathbf{Q}_{\mathbf{m}}(\mathbf{m g} / \mathbf{g})$} & \multicolumn{2}{c}{$\mathbf{K}_{\mathbf{L}}(\mathbf{L} / \mathbf{g})$} & \multicolumn{1}{c}{$\boldsymbol{R}^{\mathbf{2}}$} \\
\hline & Garlic & Ginger & Garlic & Ginger & Garlic & Ginger \\
$\mathrm{Pb}$ & 3.93 & 2.90 & 0.28 & 0.27 & 0.9605 & 0.9900 \\
$\mathrm{Cd}$ & 3.32 & 2.31 & 0.32 & 0.31 & 0.9774 & 0.9931 \\
$\mathrm{Cr}$ & 1.99 & 1.95 & 0.31 & 0.26 & 0.9913 & 0.9909 \\
\hline
\end{tabular}

3.6 Temkin Isotherm

The Temkin isotherm for adsorption of lead, cadmium and chromium ions in solution are shown in Figures 13 to 18.

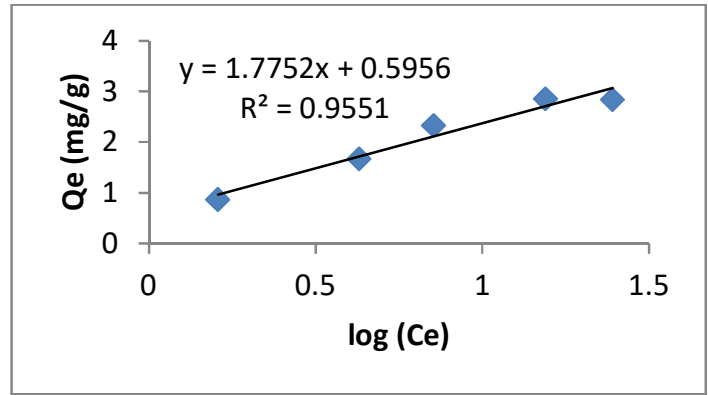

Figure 13: Temkin Isotherm for Lead Using Garlic

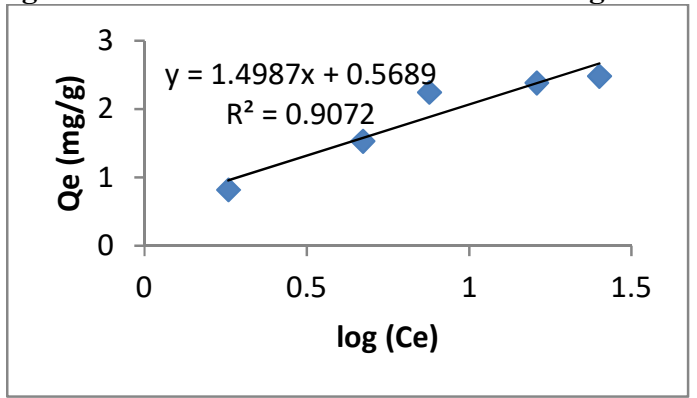

Figure 14: Temkin Isotherm for Lead Using Ginger

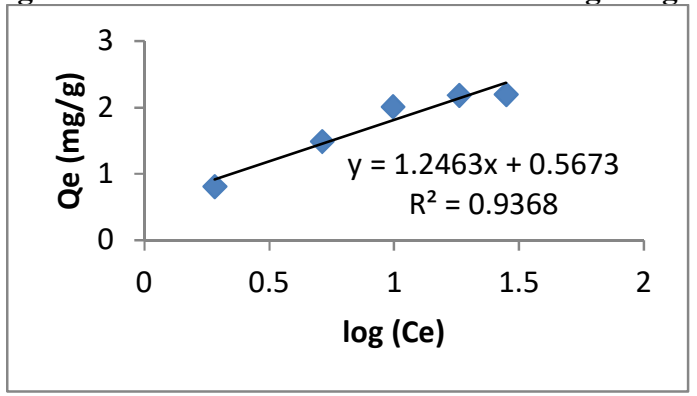

Figure 15: Temkin Isotherm for Cadmium Using Garlic

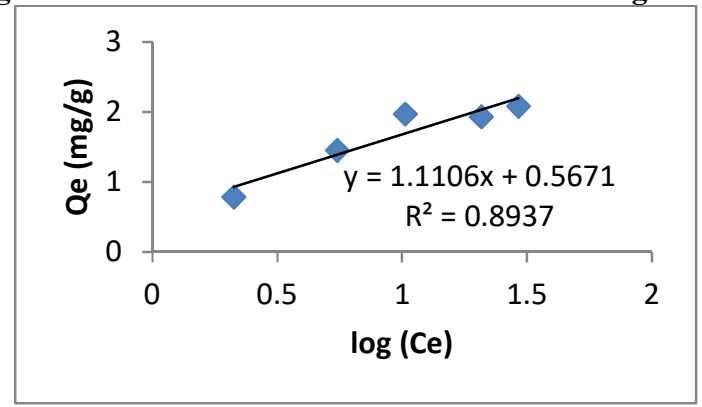

Figure 16: Temkin Isotherm for Cadmium Using Ginger 


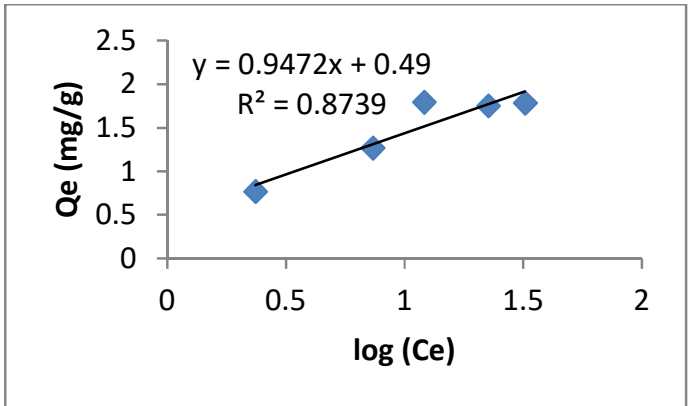

Figure 17: Temkin Isotherm for Chromium Using Garlic

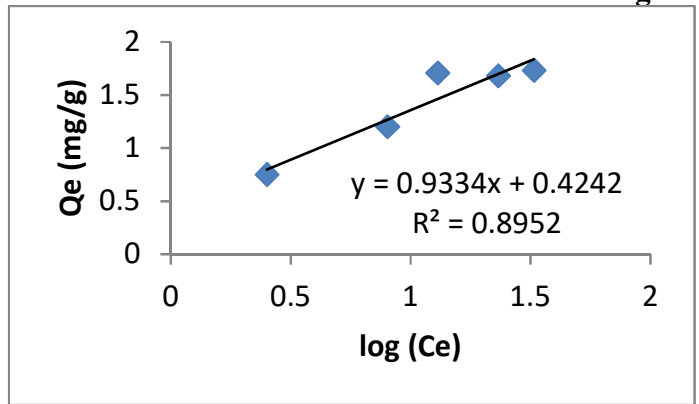

Figure 18: Temkin Isotherm for Chromium Using Ginger

The Temkin isotherm model showed increase in concentration of heavy metal uptake by the adsorbents. Again, the adsorption parameters of garlic and ginger particles relating to Temkin isotherm are summarized in Table 3.

Table 3: Summary of Temkin Isotherm Model Parameters

\begin{tabular}{lllllllllll}
\hline Metal & \multicolumn{2}{c}{$\mathbf{B}$} & \multicolumn{2}{c}{$\mathbf{C}$} & \multicolumn{2}{c}{$\mathbf{A}(\mathbf{l} / \mathbf{g})$} & \multicolumn{2}{c}{$\mathbf{b}(\mathbf{J} / \mathbf{m o l})$} & \multicolumn{2}{c}{$\boldsymbol{R}^{\mathbf{2}}$} \\
\hline & Garlic & Ginger & Garlic & Ginger & Garlic & Ginger & Garlic & Ginger & Garlic & Ginger \\
$\mathrm{Pb}$ & 1.7752 & 1.4987 & 0.5956 & 0.5689 & 1.3987 & 1.4617 & 1409.87 & 1669.79 & 0.9551 & 0.9072 \\
$\mathrm{Cd}$ & 1.2463 & 1.1106 & 0.5673 & 0.5671 & 1.5765 & 1.6663 & 2007.95 & 2253.30 & 0.9368 & 0.8937 \\
$\mathrm{Cr}$ & 0.9720 & 0.9334 & 0.49 & 0.4242 & 1.6555 & 1.5753 & 2574.60 & 2681.07 & 0.8739 & 0.8952 \\
\hline
\end{tabular}

\subsection{Adsorption Kinetics}

The kinetic study of lead, cadmium and chromium ions adsorption in solution are shown in Figures 19 to 24.

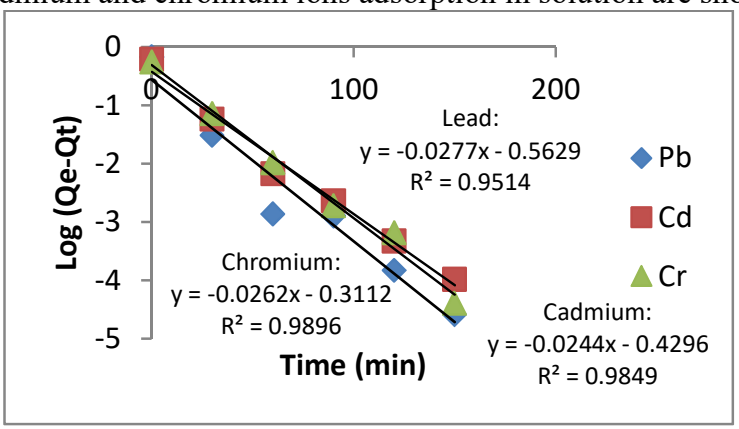

Figure 19: Pseudo $1^{\text {st }}$ Order Kinetics with Garlic Adsorbent 


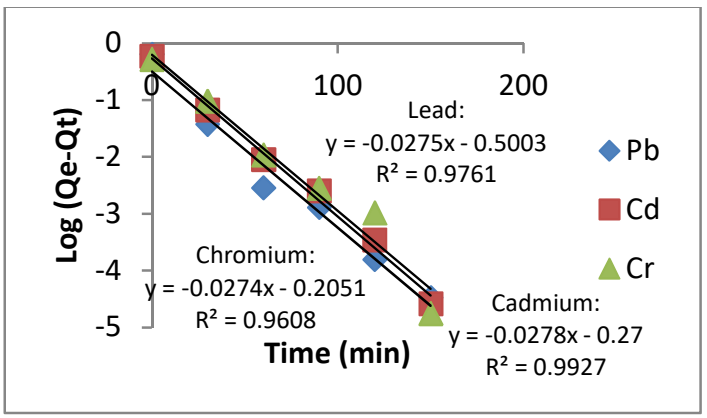

Figure 20: Pseudo $1^{\text {st }}$ Order Kinetics with Ginger Adsorbent

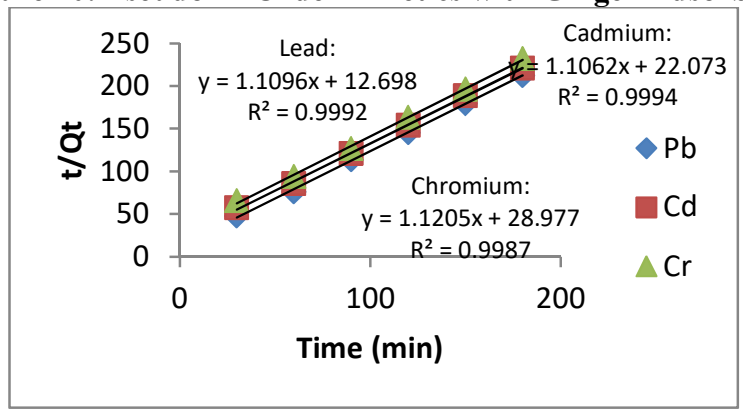

Figure 21: Pseudo $2^{\text {nd }}$ Order Kinetics with Garlic Adsorbent

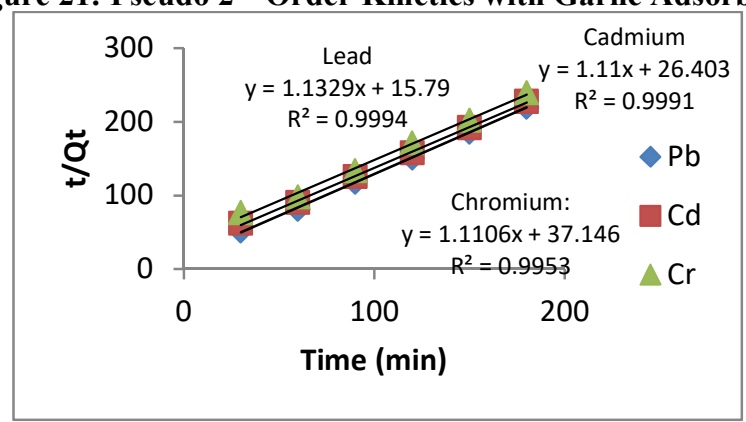

Figure 22: Pseudo $2^{\text {nd }}$ Order Kinetics with Ginger Adsorbent

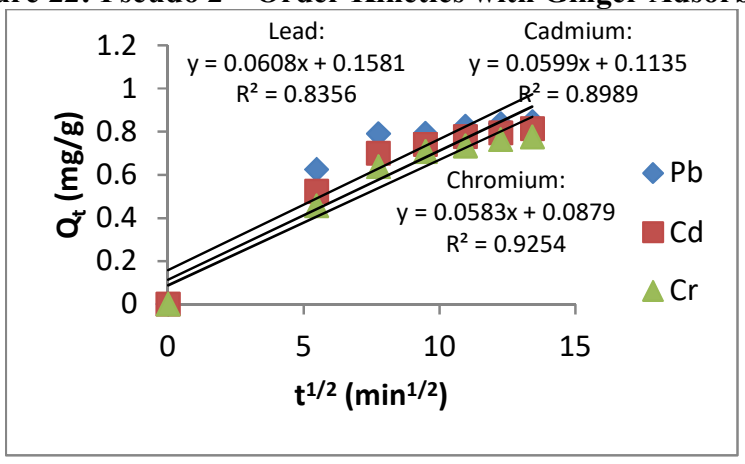

Figure 23: Intra-Particle Diffusion of Metal in Nano-Garlic Particle 


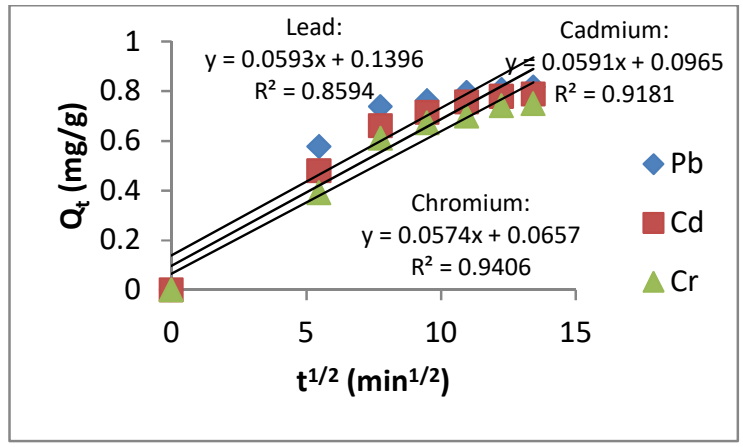

Figure 24: Intra-Particle Diffusion Kinetics of Metals in Nano-Ginger Particle

The kinetics of lead, cadmium and chromium ions adsorption onto garlic and ginger particles in solution has carried been performed to describing the adsorption process. Thus, the linear plots shown in Figures 19 to 24 revealed that adsorption of heavy metal ions did not only occur on the surface of the adsorbents but also due to chemisorption and diffusion.

The intra-particle diffusion plots alongside the Pseudo First and Second Order Kinetics helped to ascertain the mechanism and rate controlling steps of the adsorption process (Ademiluyi and Ujile, 2013). Thus, the linear lines for adsorption process did not pass through the origin for adsorption of lead, cadmium and chromium ions. Though, there was effects of diffusion and chemisorptions. Therefore, the failure of the linear plots to pass through the origin implied that the adsorption of lead, cadmium and chromium ions were not controlled by intra-particle diffusion.

Again, from Figures 23 and 24, the linear relationship for chromium ion were more close to the origin, indicating that chromium ion diffused more into the particles than cadmium and lead ions. This was also observed by other studies for adsorption of heavy metal in aqueous solution (Ademiluyi and Ujile, 2013; Li et al., 2016 and Kulkarni et al., 2017).

Table 4: Summary of Pseudo First Order Kinetic Parameters

\begin{tabular}{lllllll}
\hline Metal & \multicolumn{2}{c}{$\mathbf{Q}_{\mathbf{e}}(\mathbf{m g} / \mathbf{g})$} & \multicolumn{2}{c}{$\mathbf{k}_{\mathbf{1}}\left(\mathbf{m i n}^{\mathbf{- 1}}\right)$} & \multicolumn{2}{c}{$\boldsymbol{R}^{\mathbf{2}}$} \\
\hline & Garlic & Ginger & Garlic & Ginger & Garlic & Ginger \\
$\mathrm{Pb}$ & 0.5692 & 0.6063 & 0.0277 & 0.0275 & 0.9514 & 0.9761 \\
$\mathrm{Cd}$ & 0.6508 & 0.7634 & 0.0244 & 0.0278 & 0.9849 & 0.9927 \\
$\mathrm{Cr}$ & 0.7326 & 0.8146 & 0.0262 & 0.0274 & 0.9896 & 0.9608 \\
\hline
\end{tabular}

Table 5: Summary of Pseudo Second Order Kinetic Parameters

\begin{tabular}{lllllll}
\hline Metal & \multicolumn{2}{c}{$\mathbf{Q} \mathbf{~}(\mathbf{m g} / \mathbf{g})$} & \multicolumn{2}{c}{$\mathbf{k} \mathbf{( \mathbf { m i n } ^ { - 1 } )}$} & \multicolumn{2}{c}{$\boldsymbol{R}^{\mathbf{2}}$} \\
\hline & Garlic & Ginger & Garlic & Ginger & Garlic & Ginger \\
$\mathrm{Pb}$ & 0.9012 & 0.8827 & 0.0970 & 0.0813 & 0.9992 & 0.9994 \\
$\mathrm{Cd}$ & 0.9040 & 0.9009 & 0.0554 & 0.0467 & 0.9994 & 0.9991 \\
$\mathrm{Cr}$ & 0.8925 & 0.9004 & 0.0433 & 0.0332 & 0.9987 & 0.9953 \\
\hline
\end{tabular}

Table 6: Summary of Intra-Particle Diffusion Parameters

\begin{tabular}{llcll}
\hline Metal & \multicolumn{2}{c}{$\mathbf{K}_{\mathbf{d}}\left(\mathbf{m g} / \mathbf{g} \mathbf{~ m i n}^{\mathbf{1} / \mathbf{2}}\right)$} & \multicolumn{2}{c}{$\boldsymbol{R}^{\mathbf{2}}$} \\
\hline & Garlic & Ginger & Garlic & Ginger \\
$\mathrm{Pb}$ & 0.0608 & 0.0593 & 0.8356 & 0.8594 \\
$\mathrm{Cd}$ & 0.0599 & 0.0591 & 0.8989 & 0.9181 \\
$\mathrm{Cr}$ & 0.0583 & 0.0574 & 0.9254 & 0.9406 \\
\hline
\end{tabular}

The adsorption kinetic parameters are summarized in Tables 4, 5 and 6.

The equilibrium adsorption capacity obtained from the experiment for lead, cadmium and chromium ions were $0.8465,0.8131$ and $0.7748 \mathrm{mg} / \mathrm{g}$ with garlic nano-particles adsorbent, while with ginger nano-particles adsorbent, the equilibrium adsorption capacity were $0.8173,0.78195$ and $0.7501 \mathrm{mg} / \mathrm{g}$ for lead, cadmium and chromium ions respectively. This showed that the predicted equilibrium adsorption capacity of nano-particles of garlic and ginger by the Pseudo Second Order were closer to the experimental values than those predicted by the Pseudo First Order. This is further demonstrated by the R-squared values (Table 5). Similar observation on the comparison of First and Second Order Pseudo Kinetics had been reported in earlier studies (Li et al., 2016; Sharma et al., 2016; Azizi et al., 2017 and Kulkarni et al., 2017). 


\section{CONCLUSION}

The experimental investigation of particles of garlic and ginger for adsorption of lead, cadmium and chromium ions from contaminated water has been studied. Amount of heavy metal concentration in solution, adsorbent dosage and contact time, all has significant impact on the removal efficiency of heavy metals in aqueous solution. However, the percentage of lead, cadmium and chromium ions adsorbed decreased as the initial concentration of metals in solution increased, but increased with increase in adsorbent dosage and contact time which equally increased the percentage removal of the heavy metals from the solution due to increase in effective surface area and gathering of the adsorbent.

In comparison, garlic particles adsorbed the heavy metals more than ginger particles at all conditions, while lead ions was the most adsorbed ions followed by cadmium ion. Also, the experimental fits of the adsorption of lead, cadmium and chromium ions were better explained by the Langmuir isotherm than the Temkin isotherm.

Furthermore, adsorption of the heavy metal ions onto garlic and ginger nano-particles revealed that diffusion and chemisorptions took place in the adsorption process, but the pseudo second order kinetics predicted the adsorbed heavy metals better than the two other rate kinetics, hence, it is the rate controlling step.

\section{REFERENCES}

Ademiluyi, F. T. \& Ujile, A. A. (2013). Kinetics of Batch Adsorption of Iron II Ions from Aqueous Solution using Activated Carbon from Nigerian Bamboo, International Journal of Engineering and Technology, 3(6), 623631.

Azizi, S., Shahri, M. M. \& Mohamad, R. (2017). Green Synthesis of Zinc Oxide Nanoparticles for Enhanced Adsorption of Lead Ions from Aqueous Solutions: Equilibrium, Kinetic and Thermodynamic Studies, Journal of Molecules, 22, 831-844.

Choi, B.Y., Yun, S. T., Mayer, B. \& Kim, K. H. (2011). Sources and Biochemical Behavior of Nitrate and Sulfate in an Alluvia Aquifer: Hydrochemical and Stable Isotope Approaches, Applied Geochemical, 26, 1249-1260.

Chowdhury, A., Bhowal, A. \& Datta, S. (2012). Equilibrium, Thermodynamic and Kinetic Studies for Removal of Copper (II) from Aqueous Solution by Onion and Garlic Skin, Journal of Water, 4, 37-51.

De Gusseme, B. Vanhaecke, L., Verstraete, W. \& Boon, N. (2011). Degradation of Acetaminophen by Delftia Tsuruhatensis and Pseudomonas Aeruginosa in a Membrane Bioreactor, Water Resources, 45, 1856-1864.

Geetha, K. S. \& Belagali, S. L. (2010). Removal of Dyes and Heavy Metals Using Garlic Husk, Nature Environment and Pollution Technology, 9(2), 323-327.

Herlekar, M. \& Barve, S. (2015). Optimization of microwave assisted Green synthesis Protocol for Iron Oxide Nanoparticles and its Application for simultaneous Removal of Multiple pollutants from Domestic sewage, International Journal of Advanced Research, 3(40, 331-345.

Ho, Y. S. (2004). Citation Review of Langergren Kinetic Rate on Adsorption Reactions, Journal of Scientomertics, 59, 171-177.

Kulkarni, M. R., Revanth, T., Acharya, A. \& Bhat, P. (2017). Removal of Crystal Violet Dye from Aqueous Solution Using Water Hyacinth: Equilibrium, Kinetics and Thermodynamics Study, Resource-Efficient Technologies, 3, 71-77.

Kumar, P. S., Vincent, C. Kirthika, K. \& Kumar, K. S. (2010). Kinetics and Equilibrium Studies of $\mathrm{Pb}^{2+} \mathrm{Ion}$ Removal from Aqueous Solutions by Use of Nano-Silversol-Coated Activated Carbon, Brazilian Journal of Chemical Engineering, 27(2), 339-346.

Kumar, V. \& Shrivastava, P. (2015). An Approach to Access the Performance of Sawdust as Adsorbent for $\mathrm{Cr}$ (VI) Ions Removal from Contaminated Water, International Journal of Engineering Research and General Science, 3(4), 2091-2730.

Li, B., Zhou, F., Huang, K., Wang, Y., Mei, S., Zhou, Y. \& Jing, T. (2016). Highly Efficient Removal of Lead and Cadmium during Wastewater Irrigation Using a Polyethyleniminegrafted Gelatin Sponge, Scientific Reports, 6, 573-581.

Liang, S., Guo, X. \& Tian, Q. (2013). Adsorption of $\mathrm{Pb}^{2+}, \mathrm{Cu}^{2+}$ and $\mathrm{Ni}^{2+}$ from Aqueous Solutions by Novel Garlic Peel Adsorbent, Desalination and Water Treatment, 51, 7166-7171.

Mehra, M., Oinam, B. \& Singh, C. K. (2016). Integrated Assessment of Groundwater for Agricultural Use in Mewat District of Haryana, Indian Using geographical Information System (GIS), Journal of the Indian Society of Remote Sensing, 44(5), 196-202.

Ndamitso, M. M., Mustapha, S., Etsuyankpa, M. B., Jacob, J. O., Adeshina, I. O. \& Ekor, L. (2016). Removal of Lead, Cadmium and Cobalt from Oil Spill Water onto Soursop (Annonamuricata) Peel, Science Journal of Analytical Chemistry, 4(1), 7-11.

Negi, R., Satpathy, G., Tyagi, Y. K. \& Gupta, R. K. (2012). Biosorption of Heavy Metals by Utilising Onion and Garlic Wastes, International Journal of Environment and Pollution, 49(3/4), 179-196.

Pasavant, P. Apiratikul, R. Sungkhum, V. Suthiparinyanont, P. Wattanachira, S. \& Marhaba, T. F. (2006). Biosorption of $\mathrm{Cu}^{2+}, \mathrm{Cd}^{2+}, \mathrm{Pb}^{2+}$, and $\mathrm{Zn}^{2+}$ Using Dried Marine Green Macroalga Caulerpa Lentillifera, 
Bioresources Technology, 97, 2321-2329.

Sharma, P. K., Ayub, S. \& Tripathi, C. N. (2016). Isotherms describing Physical Adsorption of Cr(VI)from Aqueous Solution Using Various Agricultural Wastes as Adsorbents, Civil \& Environmental Engineering Research,3, 1-20.

Ujile, A. A. \& Okwakwam, C. (2018). Adsorption Process of Iron, Cadmium, Copper, Lead from Aqueous Solution using Palm Bunch Adsorbent, Chemical and Process Engineering Research, 55,11-21.

Ujile, A. A. \& Owhor, S. N. (2018). Developing Mass Transfer Model for Predicting Concentration Profiles of Contaminants in Groundwater Resource, Chemical and Process Engineering Research, 57, 67-81. 